\title{
Hidrops vesicular secundario a vólvulo: reporte de un caso
}

\author{
María Inés Gaete D. ${ }^{1,2}$, Isabel Rao S. ${ }^{1,2}$ y Manuel Manzor V. ${ }^{2}$
}

'Escuela de Medicina, Pontificia Universidad Católic de Chile.

Servicio de Cirugía Complejo Asistencial Dr. Sótero del Río. Santiago, Chile.

Recibido 2021-03-22 aceptado 2021-05-02

Correspondencia a: Dr. Manuel Manzor V. mfmanzor@uc.c

\section{Gallbladder hydrops due to vesicular volvulus: a case report}

Introduction: Gallbladder volvulus (GV) is an extremely rare cause of acute cholecystitis. Approximately 500 cases have been reported in world literature. It can lead to total obstruction of the gallbladder drainage and ischemia with a high risk of progressing to perforation and biliary peritonitis. Case report: 90-year-old woman consulted due to hypogastric pain of sudden onset, associated with painful palpable abdominal mass in the flank and right iliac fossa. Computed axial tomography of the abdomen and pelvis demonstrated an accentuated distention of the gallbladder, located outside the gallbladder fossa and with a point suggestive of torsion. She underwent exploratory laparotomy, devulvulation followed by cholecystectomy, with favorable postoperative evolution. Discussion: The development of GV requires a "floating gallbladder", its clinical picture is non-specific and is often confused with acute lithiasic cholecystitis. Its preoperative diagnosis is difficult despite the imaging study. Timely surgical intervention is the only resolutive treatment, with excellent results. Conclusion: GV is a rare pathology, it represents a diagnostic challenge for both surgeons and radiologists.

Keywords: gallbladder; gallbladder hydrops; volvulus; torsion.

\section{Resumen}

Introducción: El vólvulo de vesícula biliar (VVB) es una causa extremadamente rara de colecistitis aguda. Aproximadamente 500 casos han sido reportados en la literatura mundial. Puede generar una obstrucción total del drenaje vesicular e isquemia con alto riesgo de progresar a perforación y peritonitis biliar. Caso clínico: Mujer de 90 años consultó por dolor hipogástrico de inicio súbito, asociado a masa abdominal palpable y dolorosa en flanco y fosa ilíaca derecha. Tomografía axial computada de abdomen y pelvis demostró una acentuada distensión de la vesícula biliar, ubicada por fuera de la fosa vesicular y con un punto sugerente de torsión. Fue sometida a laparotomía exploradora, desvolvulación seguida de colecistectomía, con evolución posoperatoria favorable. Discusión: Para el desarrollo de un VVB se requiere una "vesícula flotante", su cuadro clínico es inespecífico y muchas veces es confundido con una colecistitis aguda litiásica, su diagnóstico preoperatorio es difícil pese al estudio con imágenes. La intervención quirúrgica oportuna es el único tratamiento resolutivo, con excelentes resultados. Conclusión: La VVB es una patología rara, representa un desafío diagnóstico tanto para cirujanos como radiólogos.

Palabras clave: vesícula biliar; hidrops vesicular; vólvulo; torsión.

\section{Introducción}

El vólvulo o torsión de la vesícula biliar (VVB), es una causa extremadamente rara de colecistitis aguda. Desde su primer diagnóstico publicado en $1898^{1}$, aproximadamente 500 casos han sido reportados en la literatura mundial ${ }^{2,3}$. Su incidencia ocurre principalmente en población femenina longeva con bajo índice de masa corporal (IMC). Dentro de los factores de riesgo descritos destaca la presencia de cifoescoliosis, una rápida pérdida de peso y atrofia hepática ${ }^{4}$. Su cuadro clínico es inespecífico, clásicamente descrito como dolor abdominal de inicio súbito asociado a una masa abdominal palpable. Los exámenes de laboratorio generalmente demuestran niveles de enzimas hepáticas y bilirrubina dentro de rango normal, pero con una gran elevación de los parámetros inflamatorios ${ }^{3}$. 
Su mecanismo fisiopatológico principal se basa en una "vesícula flotante" cuyo mesenterio, el cual habitualmente la recubre junto a su pedículo cístico y la sostiene unida y fija al lecho hepático, es en estos casos anormalmente largo y/o solo recubre el pedículo cístico, quedando la vesícula libre y susceptible a movilizarse y torcerse. Estos fenómenos se explican tanto por causas congénitas como adquiridas. Estas últimas, se basan en la relación inversa entre el envejecimiento del paciente y la elasticidad del tejido y grasa visceral, generando así una pérdida de soporte estructural progresiva. Teniendo presente lo anterior, y asociado a los movimientos peristálticos fisiológicos de los otros órganos del sistema gastrointestinal, la vesícula puede rotar respecto a su eje, ya sea $<180^{\circ}$ (tipo I) o $>180^{\circ}$ (tipo II) ${ }^{5,6}$. El VVB tipo I puede ser asintomático u oligosintomático, donde la vesícula se distiende progresivamente sin isquemia crítica, generando cuadros similares a un cólico biliar simple. Por otro lado, el VVB tipo II genera una obstrucción total del drenaje vesicular e isquemia, produciendo un cuadro de abdomen agudo con alto riesgo de progresar a perforación y peritonitis biliar, condiciones graves y potencialmente letales, siendo así una urgencia quirúrgica.

\section{Caso clínico}

Mujer de 90 años con antecedentes de hipertensión arterial, hipotiroidismo, síndrome de Sjögren, hipoacusia, monorrena secundario a nefrectomía izquierda, tumor anexial izquierdo benigno de $4 \mathrm{~cm}$ y obstrucción intestinal por bridas resuelta mediante laparotomía. Acudió en febrero de 2021 al Servicio de Urgencia del Complejo Asistencial Dr. Sótero del Río por dolor hipogástrico de inicio súbito, sin otros síntomas asociados. Al examen físico destacaban signos vitales estables, afebril, enflaquecida (peso $40 \mathrm{~kg}$, talla 1,45 m, IMC 19), presencia de masa abdominal dolorosa a la palpación ubicada en flanco y fosa ilíaca derecha de $12 \mathrm{~cm}$ aproximadamente. Exámenes de laboratorio compatibles con función renal y enzimas hepáticas normales asociadas a elevación significativa de parámetros inflamatorios (proteína C reactiva 352,9 mg/L, leucocitos 21.690/ uL con $95,1 \%$ neutrófilos). Se complementó estudio con tomografía axial computada (TC) de abdomen y pelvis que mostró una imagen quística hipodensa de 12 x 9,2 x 7,4 cm en flanco y fosa ilíaca derecha, de paredes bien definidas, que impresionaba ser una acentuada distensión de la vesícula biliar, ubicada por fuera de la fosa vesicular y leve engrosamiento parietal difuso, con algunas imágenes redondeadas de hasta $3,3 \mathrm{~cm}$ en su interior que podían estar determinadas por cálculos; además, el conducto cístico se encontraba en posición anómala hacia caudal con una aparente área de engrosamiento en su aspecto distal inmediatamente cercano al sitio de confluencia con la vesícula biliar, lo que podía estar en contexto de torsión (Figura 1). Se realizó laparotomía media supraumbilical exploradora revelando una vesícula de superficie lisa violácea de 13 x $8 \mathrm{~cm}$ con adherencias inflamatorias hacia intestino, compatible con un hidrops vesicular unido al hígado únicamente por su mesenterio cístico (fondo, cuerpo y bacinete libres en cavidad abdominal, "flotante"), volvulado en relación a su eje axial en sentido horario con punto de pivote en el pedículo cístico. Se realizó liberación de adherencias, con posterior desvolvulación de órgano comprometido y colecistectomía sin incidentes (Figura 2). Posteriormente a ello, la paciente evolucionó favorablemente, con resolución del dolor y normalización de parámetros inflamatorios, siendo dada de alta 72 h poscirugía. Estudio histopatológico de pieza operatoria compatible con vesícula biliar con litiasis y signos de colecistitis crónica inespecífica con reagudización úlcero-necrótica.

\section{Discusión}

En la literatura actual se describe la necesidad de una "vesícula flotante" para producir un $\mathrm{VVB}^{6,7}$, condición presente en nuestro caso y explicado por factores de riesgo tanto congénitos como adquiridos, como son la fijación vesicular a hígado solo por el mesenterio cístico y la longevidad de la paciente. Asimismo, presentó también un hidrops vesicular, patología entendida como una acentuada distensión de la vesícula secundaria a algún tipo de obstrucción del drenaje biliar, donde las sales biliares son absorbidas por la mucosa vesicular, generando edema de mucosa y contenido acuoso o mucocele (se ha descrito acumulación de bilis de hasta 1.500 $\mathrm{ml})^{8}$. Esta obstrucción es generalmente causada por cálculos impactados, pero puede ser también generada por pólipos, tumores, parasitosis y/o una torsión. Teniendo esto presente, la existencia de hidrops vesicular en nuestra paciente es probablemente explicada por la combinación de colelitiasis y un VVB tipo I de larga data; y cuya existencia contribuyó finalmente al desarrollo de una torsión completa (VVB tipo II), desencadenando el cuadro sintomático agudo.

En relación al rol de la litiasis en el origen de un VVB, este es actualmente incierto y cuestionable, ya 


\section{CASOS CLÍNICOS}

Figura 1. TC de abdomen y pelvis de la paciente que muestra una vesícula biliar flotante ubicada por fuera de la fosa vesicular, acentuadamente distendida; con flechas que demuestran el sitio de torsión a nive del pedículo cístico.
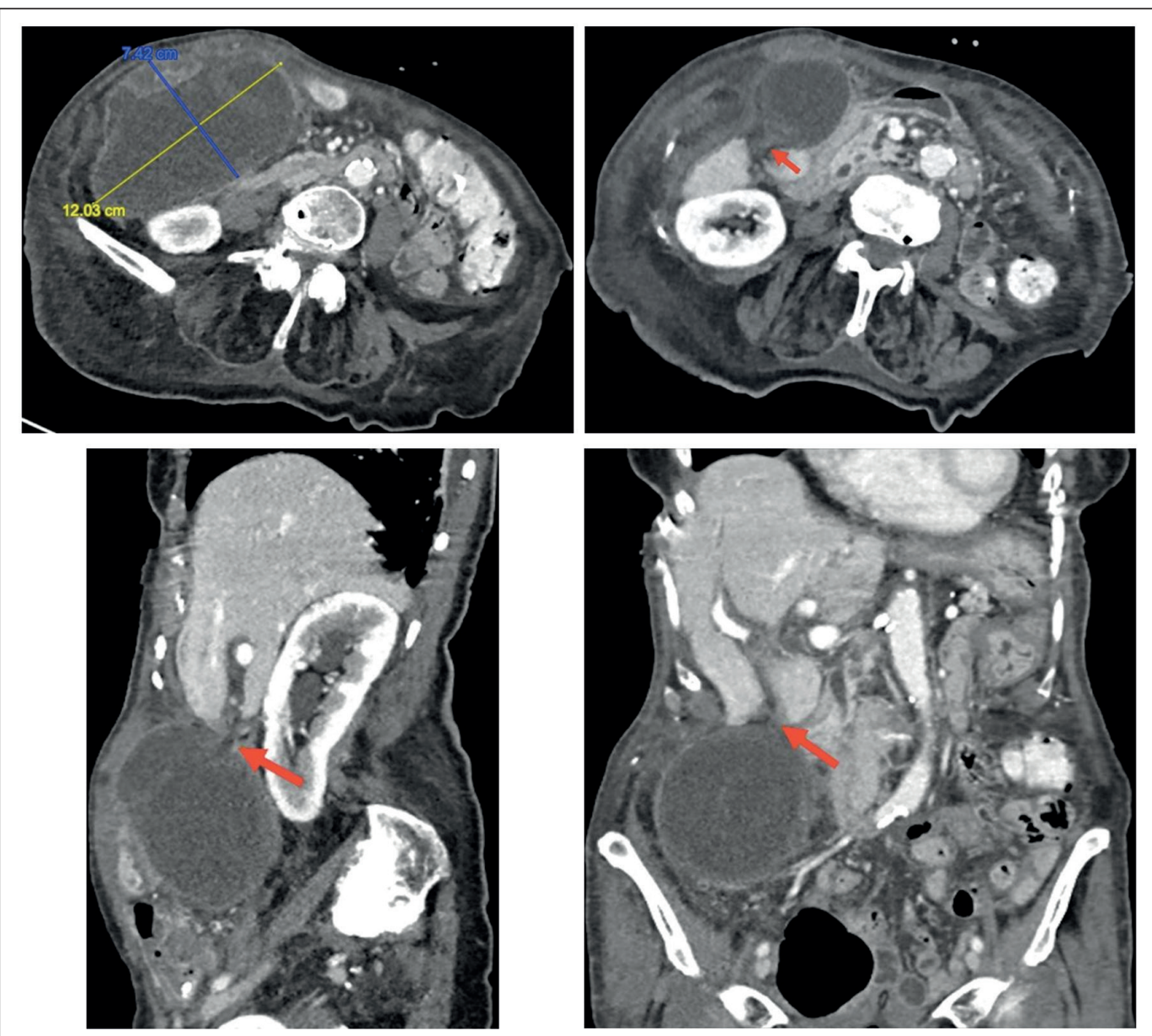

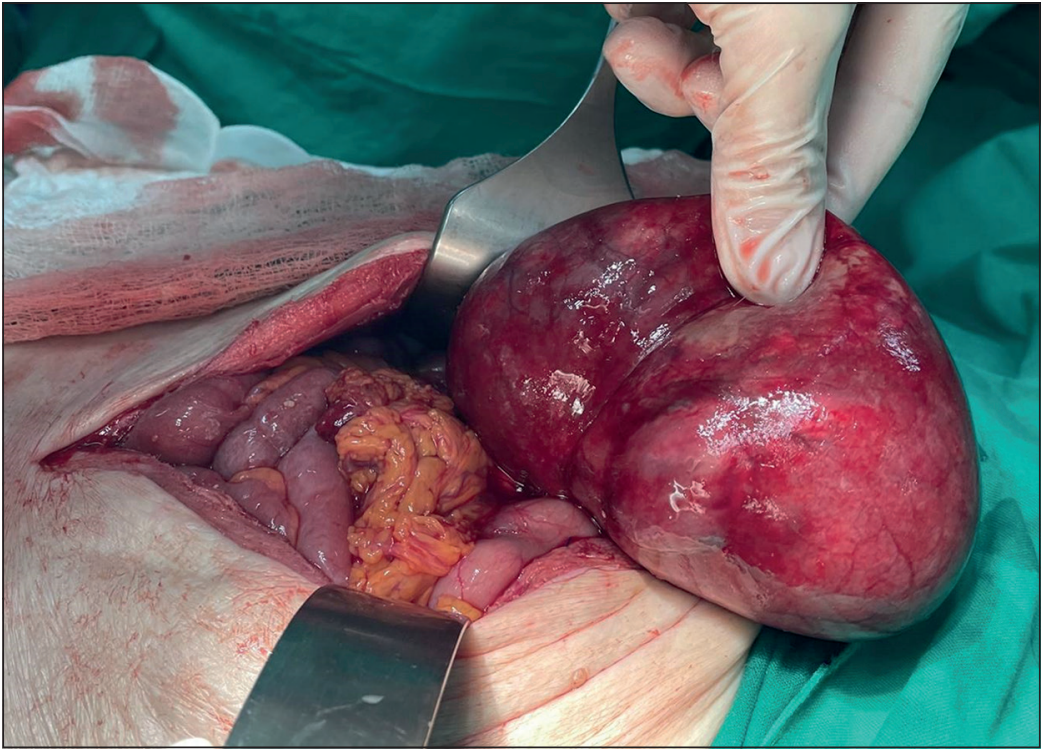

Figura 2. Imagen intraoperatoria de vesícula biliar distendida y "flotante", luego de ser desvolvulada en sentido anti-horario en relación a su pedículo cístico. que solo se ha reportado la presencia de cálculos en el 24,4-32\% de los casos, de manera que su presencia se postula más como un hallazgo incidental que como una variable causal ${ }^{9}$.

Dado la similitud del cuadro clínico a una colecistitis aguda litiásica y la gran dificultad de su diagnóstico por imágenes pese a los avances tecnológicos, sólo se han reportado en la literatura 5 casos con diagnóstico imagenológico previo a la cirugía ${ }^{7}$, siendo la mayoría de los VVB diagnosticados en el intraoperatorio. Algunos signos observados en imágenes que permiten sospechar un VVB incluyen la presencia de vesícula biliar distendida, fuera de su fosa anatómica normal, con una estructura cónica engrosada correspondiente al pedículo torcido. Actualmente, el método de estudio imagenológico de elección para esta patología es la colangioresonancia nuclear magnética (CRNM), ya que permite evaluar de manera precisa el conducto cístico, cuello vesicular, presencia y grado de inflamación, y necrosis de pared vesicular; pese a lo anterior, la CRNM 
presenta un costo elevado y no está ampliamente disponible. Por otro lado, la ecografía abdominal es el método más costo-efectivo en estos casos, entregando información respecto a la presencia de colelitiasis, ubicación vesicular, sus paredes, distensión de esta, presencia de líquido perivesicular, entre otras; sin embargo, esta tiene limitaciones como son, por ejemplo, la baja resolución a nivel de vía biliar distal y su naturaleza operador dependiente. En esta oportunidad el diagnóstico se realizó mediante un TC y, pese a no ser el examen imagenológico ideal además de la infrecuencia de esta patología, permitió identificar el origen del cuadro de manera preoperatoria, siendo así este el 6to caso diagnosticado de esta forma que se publica en la literatura.

Frente a un paciente con abdomen agudo en que se sospecha patología biliar, es importante considerar como diagnóstico diferencial a esta rara enfermedad, sobre todo en un grupo seleccionado de pacientes de edad avanzada en los cuales a veces se plantea un tratamiento inicial médico conservador no quirúrgico. La intervención quirúrgica oportuna del VVB es el único tratamiento resolutivo, con excelentes resultados posoperatorios como se demuestra en nuestro caso. Se debe hacer hincapié que, al igual a como se describe en la literatura ${ }^{3,10}$, solo hubo compromiso de los parámetros inflamatorios a nivel de exámenes bioquímicos, de manera que niveles normales de enzimas hepáticas no descartan el diagnóstico de VVB y no se debe esperar que exista una alteración de estos niveles para decidir un manejo quirúrgico. Adoptar un manejo expectante en primera instancia solo atrasaría la resolución del cuadro y repercutiría negativamente en la morbimortalidad del paciente.

La destorsión y colecistectomía pueden ser realizadas tanto por vía laparoscópica como laparotomía ${ }^{3,7,10}$. En el caso de la vía laparoscópica, casi siempre es necesario realizar una descompresión y aspiración del contenido vesicular de manera de facilitar su desvolvulación previo a su extracción. En este caso reportado, se prefirió el abordaje quirúrgico vía laparotomía dado el tamaño de la lesión en relación a la contextura de la paciente y el antecedente de laparotomía previa por obstrucción intestinal.

\section{Conclusión}

El VVB es una patología rara, representa un desafío diagnóstico tanto para cirujanos como radiólogos, siendo la mayoría de los cuadros diagnosticados en el intraoperatorio. Si bien es de las causas menos frecuentes de colecistitis aguda, es importante tener en cuenta su existencia y diagnóstico oportuno, ya que puede cambiar la estrategia terapéutica. Se debe sospechar en pacientes de edad avanzada, con bajo IMC, que presentan dolor abdominal agudo con masa palpable, pudiendo estar asociado a parámetros inflamatorios elevados y que pueden presentar al estudio imagenológico una vesícula biliar distendida en posición no habitual. Se debe tener en consideración que niveles normales de enzimas hepáticas no descartan el diagnóstico. Su único tratamiento resolutivo es quirúrgico, el cual debe realizarse de manera precoz y así disminuir la morbimortalidad de nuestros pacientes.

\section{Responsabilidades éticas}

Protección de personas y animales. Los autores declaran que para esta investigación no se han realizado experimentos en seres humanos ni en animales.

Confidencialidad de los datos. Los autores declaran que en este artículo no aparecen datos de pacientes.

\section{Conflictos de interés: no hay.}

El caso clínico presentado cuenta con la aprobación del Comité Ético Científico del Servicio de Salud Metropolitano Sur Oriente.

\section{Bibliografía}

1. Wendel AV. VI. A Case of Floating GallBladder and Kidney complicated by Cholelithiasis, with Perforation of the Gall-Bladder. Ann Surg. 1898;27:199-202.

2. Reilly DJ, Kalogeropoulos G, Thiruchelvam D. Torsion of the gallbladder: a systematic review.
HPB (Oxford) 2012;14:669-72. doi: 10.1111/j.1477-2574.2012.00513.x.

3. Wood BE, Trautman J, Smith N, Putnis $\mathrm{S}$. Rare case report of acalculous cholecystitis: Gallbladder torsion resulting in rupture. SAGE Open Med Case Rep. 2019;7:2050313X18823385. Published 2019 Jan 11. doi: $10.1177 / 2050313 X 18823385$.
4. Aljoe J. Gallbladder volvulus-acute cholecystitis 'with a twist'. J Surg Case Rep. 2018;2018:rjy303. Published 2018 Nov 19. doi: 10.1093/jscr/rjy303.

5. Puga R, Sabater C, Ramia JM, Quiñones JE, García-Parreño J. Torsión de la vesícula biliar [Gallbladder torsion]. Cir Esp. 2010;88:270-1. doi: 10.1016/j. ciresp.2009.11.014. 


\section{CASOS CLÍNICOS}

6. Hwang Y, Kulendran K, Ashworth J. Expect the Unexpected: Torsion of the Gallbladder, a Rare Cause for Acute Cholecystitis. Cureus. 2018;10:e3726. Published 2018 Dec 13. doi: 10.7759/ cureus.3726.

7. Farhat W, Mabrouk MB, Ammar H, Mizouni A, Said MA, Lagha S, et al. Gallbladder volvulus: A case report and review of the literature. Int J Surg Case
Rep. 2019;60:75-78. doi: 10.1016/j. ijscr.2019.02.025.

8. Jones MW, Deppen JG. Gallbladder Mucocele. [Updated 2021 Feb 8]. In: StatPearls [Internet]. Treasure Island (FL): StatPearls Publishing; 2021 Jan. Available from: https://www.ncbi.nlm.nih.gov/books/ NBK513282/.

9. Nakao A, Matsuda T, Funabiki S, Mori T, Koguchi K, Iwado T, et al.
Gallbladder torsion: case report and review of 245 cases reported in the Japanese literature. J Hepatobiliary Pancreat Surg. 1999;6:418-21. doi: 10.1007/ s005340050143.

10. López-Casillas N. Vólvulo de la vesícula biliar como causa de abdomen agudo. Reporte de caso y revisión de la literatura. Rev Chil Cir. 2017;69:479-82. doi: 10.1016/j.rchic.2016.12.004. 